
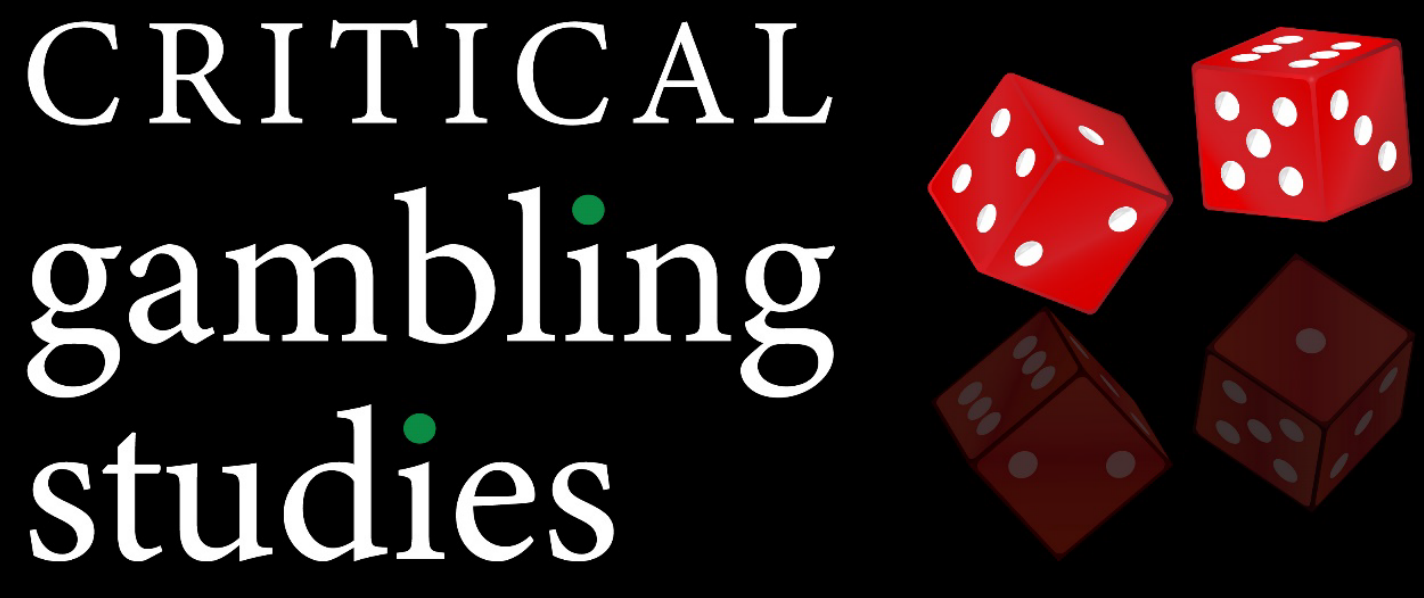

ISSN: 2563-190X. Available Open Access at https://criticalgamblingstudies.com

\title{
Social Costs of Gambling Harm in Italy
}

Fabio Lucchini, Simona Lorena Comi

APA Citation: Lucchini, F., \& Comi, S. L. (2022). Social Costs of Gambling Harm in Italy. Critical Gambling Studies, 3(1), 71-82. https://doi.org/10.29173/cgs50

Article History:

Received 2020-05-19

Accepted 2021-10-08

Published 2022-03-07 


\title{
Social Costs of Gambling Harm in Italy
}

\author{
Fabio Lucchini ${ }^{\mathrm{a} 1}$, Simona Lorena Comi ${ }^{\mathrm{b}}$
}

a PhD, Faculty of Law, eCampus University, Novedrate, Como, Italy
${ }^{b}$ PhD, Department of Business and Law, University of Milano-Bicocca, Italy

\begin{abstract}
The aim of this study is to provide an estimate of the social costs of gambling in Italy. In line with other research on social costs, the present study estimates the consequences of gambling harm on public finances, focusing on the estimated costs to treat high-risk gamblers, costs associated with productivity losses, costs of unemployment, personal and family costs, crime and legal costs. We used two different approaches to calculate these costs. The first approach, used for health care costs, consists of using the lump sum spent to prevent the harm caused to high-risk gamblers. The second approach involves estimating the number of high-risk gamblers causing the cost, which is then multiplied with the average unit cost per person. Our estimates of the annual social costs of gambling in Italy - more than EUR 2.3 billion - demonstrate a substantial economic burden to society. However, the costs are a substantial underestimate, as they are limited to those of a public nature and do not take into consideration those costs borne by moderate and low-risk gamblers, as well as affected others.
\end{abstract}

Keywords: Gambling; gambling harm; high-risk gamblers; social costs; public finances; addiction

Article History: Received May 19, 2020; Accepted October 8, 2021; Published March 7, 2022

Available Open Access from https://doi.org/10.29173/cgs50

\section{Introduction and Theoretical Framework}

It is widely recognized that different forms of addiction entail social costs to the community. In particular, several types of social costs related to gambling have been identified in the literature. These include, on the one hand, the costs for treatment (direct costs), and, on the other, the costs related to productivity loss, unemployment benefits, civil and criminal justice, social security system, etc. (indirect costs) (Anielski \& Braaten, 2008). Specifically, the concept of social cost, widely used in economic literature on addictions (Walker, 2007), refers to an overall loss of social welfare attributable to certain choices, actions and behaviors.

It is also important to consider the inherent difficultly involved in defining the concept of gambling behavior. In fact, the distinction between different stages of gambling behavior, from social gambling to problem gambling, is very complex particularly in the absence of a diagnosis by a psychiatrist, a clinical psychologist or a psychotherapist (Barbaranelli, 2015). The conceptualization of problem gambling proposed by Neal, Delfabbro and O'Neil (2005) focuses on difficulty limiting the money and time spent in gambling. This difficulty leads to negative consequences for the gambler, significant others, and for the community. "Pathological gambling" is the principal term used in medical literature and is defined largely in terms of the mechanisms which are central to substance use disorders (cravings, tolerance and withdrawal), while 'problem gambling' - referring to a public health conceptualization - defines the disorder largely in terms of its harmful consequences. Commonly used psychometric measures of the disorder include variables relating to both behavioral indicators of pathology as well as harmful impacts (Delfabbro, 2013). In this article, we use the concept of "gambling harm", to avoid labelling and stigmatization effects (Livingstone \& Rintoul, 2021).

Given the complexity of the subject, it is not surprising that the adequacy of what should or should not be included in the concept of social cost has long been debated. Walker and Barnett (1999) rely on welfare economics theory to explain that the social cost of an action is equal to the reduction of aggregate wealth caused by that particular action. They exclude

\footnotetext{
${ }^{1}$ Corresponding author. Email: lucchinifabio@tiscali.it

Fabio Lucchini wrote the following paragraphs: "Introduction and theoretical framework", "Methods" and "Discussion". Simona Comi and Fabio Lucchini wrote together "Calculation of costs".
} 
wealth transfers, private costs and pecuniary externalities related to gambling, which may redistribute wealth on a social level without reducing aggregate wealth. Collins and Lapsley (2003) focus on the distinction between tangible and intangible social costs (worsening of quality of life, stress, etc.), which are extremely difficult to evaluate using standard economic measures.

From the wide range of approaches to identifying and measuring the socio-economic effects of gambling harm, three academic streams have emerged: the costof-illness (COI) approach, the economic approach, and the public health perspective (Korn et al., 2003). In line with the COI approach, the impact of high-risk gambling on societal well-being can be estimated by examining the social costs of treatment, prevention, research, law enforcement, productivity loss and quality of life reduction, comparing them to a counterfactual scenario in which high-risk gambling is hypothetically absent. The economic approach also takes into consideration gambling benefits (social gamblers, satisfied consumers, local economy development, tax revenues), linking the concept of social costs to the overall wealth of a society, not just to aggregate material wealth. The public health perspective aims at a synthesis and includes prevention, harm reduction and quality of life in the costs estimates. Each approach has convincing arguments, but also limitations that require further investigation and revision. The common assumption is that gambling harm involves costs for society, but there is disagreement on what should be considered 'social' versus 'private' costs.

Therefore, estimates vary considerably, within and between jurisdictions, according to the methodologies proposed. A Swiss study analyzed gambling harmrelated quality of life reduction, estimating $\mathrm{CHF} 3,830$ for each high-risk gambler, equal to over $20 \%$ of the overall social costs of gambling (Jeanrenaud et al., 2012; Kohler, 2014). Moreover, according to an Australian study, reduction in quality of life accounts for $90 \%$ of gambling-related social costs, where each high-risk gambler would involve in his hardships from 5 to 10 people in the wider family and friendship group (Productivity Commission, 1999, 2010). A more recent study, estimating the number of affected-others associated with high-risk gamblers, concludes that a point-estimate of six people affected is a more accurate figure since it does not suffer from self-presentation effects of high-risk gamblers (Goodwin et al., 2017).

The study of social costs associated with gambling in Victoria, Australia (Browne et al., 2017) broadens the calculation to include all gambling severity levels. Including low, moderate, and high-risk gambling categories, the total cost of gambling in Victoria in 2014-15 was estimated to be AUD 7 billion: AUD 2.2 billion in family and relationship problems; AUD 1.6 billion in emotional and psychological issues, including suicide and violence; AUD1.35 billion in financial losses; AUD1.15 billion in costs such as research, regulation, and professional support services; $\$ 600$ million in lost productivity and other work-related costs; AUD100 million in costs of crime and the justice system. Considering the similarities between the German and Italian health and welfare systems, it is interesting to consider what emerges from a study conducted by Becker (2011), which provides an estimate of the total social costs of gambling harm (EUR 326 million), without considering intangible costs such stress and quality of life reduction. An effort at generalization - related to the social costs of drugs but extensible to behavioral addictions - is represented by the international guidelines proposed by Single et al. (2003) and recently resumed by Barrio et al. (2017). Also taking into consideration more recent research on the social costs of gambling (Winkler et al., 2017), several cost components are identified: health and social care costs; productivity costs (loss of employment or productivity); family costs; penitentiary and judicial system costs; other costs which vary depending on the type of addiction and intangible costs (e.g., stress and quality of life reduction) (Table 1).

Table 1. Comparison between studies on the Social Cost of Gambling (euros)

\begin{tabular}{|c|c|c|c|c|c|c|c|}
\hline Country/Costs & Health & $\begin{array}{l}\text { Unemploy./ } \\
\text { productivity }\end{array}$ & Family & Crime/legal & Suicide & Other & Total \\
\hline & & & & & & & $\begin{array}{l}541,600,000 \\
619,600,000\end{array}$ \\
\hline & & $37,718,000-$ & & $70,799,000$ & - $185,000,000-$ & 4,943 & (per capita: \\
\hline Czech Rep. & $1,508,000$ & $71,836,000$ & $241,261,000$ & $80,741,000$ & $214,000,000$ & 9,889 & EUR 52-59) \\
\hline & & & & & & & $\begin{array}{l}326,064,600 \\
\text { (per capita: }\end{array}$ \\
\hline Germany & $49,860,000$ & $185,714,600$ & $15,900,000$ & $48,200,000$ & - & $26,390,000$ & $\begin{array}{l}\text { EUR 4) } \\
4.627,000,000^{2}\end{array}$ \\
\hline Victoria (Aus) & $760,150,000$ & $396,600,000$ & $1,454,200,00$ & $66,100,000$ & $1,057,600,000$ & $892,350,000$ & $\begin{array}{l}\text { (per capita: } \\
\text { EUR 715) }\end{array}$ \\
\hline
\end{tabular}

\footnotetext{
${ }^{2}$ The Victoria study is only partially comparable to the other two because it captures not just high-risk but also low-risk and moderate-risk gamblers.
} 
Regardless of the theoretical approach chosen, studies of social costs are generally based on assumptions that should be interpreted as an approximation of reality. In this regard, their quality is highly dependent on the opportunity to retrieve and extract data, and in many countries much still needs to be done to improve data management. In particular, the lack of primary data represents one of the most relevant weaknesses in estimating social costs in several jurisdictions

\section{Methods}

The aim of this paper is to provide an estimate of the social costs determined by a particular subgroup of the population, high-risk gamblers. In line with other research on social costs (Godfrey et al., 2002), the present study estimates the consequences of gambling harm on Italian public finances in 2014. It could provide an indication of the potential savings derived from possible policy interventions if prevention measures were introduced. However, not all costs would necessarily be reduced by any virtuous measures (e.g., high-risk gambling prevention campaigns) impacting on public health. Our empirical strategy consists of three steps. First, we defined the types of cost included in our study. Second, the population of high-risk gamblers is defined. Third, each cost is defined and computed.

\section{Types of cost}

Our analytical strategy is focused on the potential effects of being high-risk gamblers (compared to not being high-risk gamblers), for each different type of social costs typically considered in the literature. The effects are discussed for each type of social costs, although overlaps and associations might exist, to estimate both the number of people having adverse gambling consequences and the cost per person (or unit cost). This analysis focuses on the estimation of the costs directly related to high-risk gamblers, i.e. the costs to treat them, and to tackle other consequences of their harmful condition (costs associated with their productivity losses, costs of their unemployment to the society, their personal and family costs, their crime and legal costs, etc.) (Table 2). The availability of suitable data is then required to include a cost category in our exercise, even though the main costs that emerged from the literature review are included. Considering that data specifically collected on the estimation of social costs is scarce in Italy, it was necessary, where possible, to adapt data retrieved from other sources and/or originally collected for different goals. ${ }^{3}$

Table 2. Social Costs of Gambling (types)

\begin{tabular}{l|l}
\hline $\begin{array}{l}\text { Health and social care } \\
\text { Unemployment and productivity }\end{array}$ & $\begin{array}{l}\text { Costs associated with treatment and other services (morbidity and co-morbidity, } \\
\text { prevention, research and other public sector costs) } \\
\text { Costs of unemployment benefit and productivity losses } \\
\text { Suicide }\end{array}$ \\
$\begin{array}{l}\text { Family and relationship problems } \\
\text { Crime and legal }\end{array}$ & $\begin{array}{l}\text { Costs of separations and divorces } \\
\text { Penitentiary and judicial system costs }\end{array}$ \\
\hline
\end{tabular}

\section{Gambling Harm in Italy}

We derive our estimates of gambling harm prevalence in Italy using the CIRMPA study, conducted by the Department of Psychology, Sapienza University of Rome in 2008, 2010, 2012 and 2014. This was conducted on a representative sample of Italian gamblers who had distinctive characteristics associated with being high-risk gamblers, and it identified main protection and risk factors. With specific reference to 2014, a representative sample of the Italian adult population who had participated in gambling in the previous 12 months was assessed. In particular, two assessment measures, the South Oaks Gambling Screen (SOGS) - a twenty-item scale developed to screen for

\footnotetext{
${ }^{3} \mathrm{~A}$ reduction/increase in the number of high-risk gamblers can also create indirect costs/benefits, as for example with the employment effects of alternative uses of gambling revenue or different uses of
}

pathological gambling in clinical populations - and the Problem Gambling Severity Index (PGSI) - a nine-item scale designed for gambling harm screening in a normal population - were administered to 2,030 participants (Barbaranelli et al., 2013). PGSI and SOGS investigate a common core of behaviors, but also consider different aspects, complementing each other. Following Barbaranelli et al. (2013), resulting classifications were merged and those who scored the highest in at least one of two classifications were considered high-risk gambler and at risk gamblers.

gambling expenditures. The analysis of these issues, though extremely important, is beyond the scope of this paper and left to further research. 
The combined use of SOGS and PGSI, while considering an adult population of $50,624,663$ individuals (ISTAT - National Institute of Statistics 2014), results in the following projection (Table 3$)^{4}$ :

Table 3. Prevalence of at risk Categories in Italy, 2014

\begin{tabular}{l|ll}
\hline SOGS/PGSI & $\boldsymbol{N}$ & $\%$ \\
Non gamblers, social and low-risk gamblers & $49,394,484$ & 97.57 \\
High-risk and at risk gamblers & $1,230,179$ & 2.43 \\
Total & $50,624,663$ & 100 \\
\hline
\end{tabular}

According to other studies, the estimate of high-risk gamblers in Italy ranges from 1.3 to $3.8 \%$ of the general population, from 767,000 to 2,296,000 adults (Department of Anti-Drug Policies, 2015; National Institute of Health, 2018). We will use both these alternative measures of the prevalence of gambling harm to evaluate different scenarios relating to the social costs of gambling harm.

\section{Calculation of Costs}

We used two different approaches to calculate the costs. The first approach, used for health care costs, consists of using the lump sum spent to prevent and treat the harm caused to high-risk gamblers. The second approach involves estimating the number of high-risk gamblers causing the cost, which is then multiplied with the average unit cost per person. We were able to use the CIRMPA data for 2014 to estimate the unemployment incidence. For all the other costs, we had to rely on relative risks estimated by other studies and compute the number of high-risk gamblers involved. To do so, we computed the average incidence of each phenomenon in the population (ptot) and, using the relative risk (RR) and the shares of high-risk gamblers (w2) and non high-risk gamblers (w1) in the population, we computed the incidence of high-risk gamblers, p2, as p2 = ptot $/[(w 1 / R R)+w 2] . P 2$ is then multiplied by the total number of high-risk gamblers in Italy to compute the number of individuals involved. Finally, we follow the literature and include a $20 \%$ markdown in estimates to account for the uncertainty around causality (i.e., gambling leading to unemployment or suicide). This markdown is not applied to lump sum or direct costs of treatment for which the number of patients is not estimated, but taken from the actual register of patients.

\section{Health and Social Care Costs}

According to Lovaste (2016), organizational costs for a therapeutic outcome should be divided into variable health cost (direct and indirect) and fixed cost. Direct

\footnotetext{
${ }^{4}$ The division of the adult Italian population into "social and low-risk gamblers" and "high-risk and at risk gamblers" suggests that every adult in Italy gambles. This is obviously unlikely, but an assumption
}

costs represent the costs of services provided to patients (clinical interviews, telephone activities, counseling, group psychotherapy, etc.). Indirect health costs are related to services not directly addressed to patients (team meetings, clinical supervision, mentorship, etc.) but essential for a therapeutic outcome. Fixed costs include the costs for the effectiveness and maintenance of the addiction services' facilities (utilities, equipment, etc.). Comprehensive health costs are obtained by multiplying the optimal time to deliver a therapeutic outcome for the cost of professionals involved (medical doctors, nurses, social workers, etc.).

With specific reference to the treatment of gambling disorders two regional cases - Trentino Alto-Adige and Lombardy, in Northern Italy - were analyzed. Trentino Alto-Adige and Lombardy are among the highest performing Italian regions with reference to satisfaction regarding health services and the effectiveness of health care expenditure (Health Performance Index, 2017; d'Angela et al., 2019). Therefore, their health systems might represent a benchmark, both in term of efficiency (lower cost) and number of hours devoted to each patient, towards which the other regions should theoretically tend. At the moment, data availability of such detail is limited to a few territories, allowing nevertheless a first estimate of the gambling harmrelated health costs, generalizing them to the entire national context. Finally, we computed the averages of both hourly cost and number of hours in the two regions, Lombardy and Trentino Alto- Adige. Our estimates are thus conservative, and it is likely that these parameters could be higher in other regions.

On the one hand, in 2014 the Italian addiction services devoted on average 15 hours to each patient with disordered gambling and patient cost per hour was EUR 51.6. On the other hand, according to the official Report to the Italian Parliament on the state of drug addiction (Department of Anti-Drug Policies, 2016), at the beginning of 2015 the public addiction service was caring for 13,136 high-risk gamblers.

was made that the population of non-gamblers is similar to "social and low-risk gamblers" and therefore it was included in this latter category. 
So, it was possible to calculate the total national cost related to the treatment of high-risk gamblers as follows:

Patient cost per hour $X$ hours devoted to each patient $X$ patients in charge $($ EUR $51.6 \times 15 \mathrm{~h} \times 13,136)=$ EUR 10.2 million

Moreover, the Law 208/2015 (Italian Parliament, 2015) established a yearly lump sum of EUR 50 million in a Problem Gambling Fund, which is managed by the Italian Ministry of Health and by Regions, in order to guarantee prevention (Ministry of Health, 2016). The funds are tendered regularly to prevention projects. Consequently, health and social care costs of gambling harm were estimated to be EUR 60.2 million, an amount that comprises both the costs of treatment and the costs of prevention.

\section{Costs of Unemployment and Associated with Productivity}

Among the major social costs associated with gambling harm are job loss and decreased productivity at work due to frequent absences, negligence and requests for payments in advance, which often trigger a path of progressive social descent.

According to CIRMPA, in 2014 high-risk and at risk gamblers in Italy would amount to $2.43 \%$ of the general population. Therefore, to estimate the social cost of unemployment we used a $6 \%$ differential in unemployment rate as found by Lucchini and Comi (2018). In that study the authors estimated a probit model with sample selection correction (command heckprobit in Stata 16). In the selection equation, the probability of having a job was estimated over a set of standard individual characteristics (gender, age and education) and a dummy variable indicating whether the individual is a high- risk gambler. Marital status, having children and regional dummies were also added to the specification and they act as exclusion restrictions in the selection equation. The probability of being unemployed was estimated over the same covariates (gender, age, education and a dummy indicating whether the individual is a high-risk gambler). A statistically significant differential in the probability of being unemployed associated with being a high-risk gambler was found (marginal effect indicates a differential in the probability of being unemployed equal to $6 \%$ ).

Under the assumption of a causal relation between gambling harm and unemployment, and after applying $20 \%$ markdown, we estimated that in 2014 on average 59,049 individuals were unemployed due to gambling harm. Therefore, by multiplying that value for the unemployment benefits provided by the Italian government it was possible to estimate gambling harmrelated costs of unemployment.

By using National Institute of Social Security (INPS) data, it emerges that the Social Insurance
Unemployment Benefit (ASpl) in 2014 was EUR 13,783 million, while individuals who received in the same year at least one day-benefits were 2,123,303 (INPS 2015).

Since we do not observe the average length of benefit duration for high-risk gamblers, we work under the conservative assumption that the average length of benefit has the same distribution in the general population, and the information about this distribution is fully incorporated in the mean of the length of unemployment spells. So, it was possible to calculate the average gross cost to the National Institute for each unemployed person affected by gambling harm as follows:

\section{EUR 13,783,000,000/2,123,303 individuals = EUR 6,491}

We then computed the total cost due to unemployment associated with gambling harm:

EUR 6,491 X 59,049 unemployed due to gambling = EUR 383.3 million

To estimate the loss of productivity, income was used as a proxy. Furthermore, the median length of unemployment was estimated to be around 180 days in the years 2010-2013 (Maschio, 2016), thus we calculated as if the loss of productivity involved only half a year of forgone earnings. Considering that the average gross yearly income in 2014 was 29,472 (ISTAT, 2016), on average each individual unemployed because of gambling harm lost 14,736 EUR:

\section{EUR 14,736 X59,049= EUR 870.1 million}

Finally, the total cost of unemployment and productivity loss associated with gambling harm was:

\section{EUR 383.3 + EUR 870.1 = EUR 1,253.4 million}

\section{Suicidality and Suicide Costs}

Among the consequences of gambling harm, there are costs of serious suicidal thoughts and costs of attempted suicide (Custer, 1982; Grant \& Potenza, 2004; Productivity Commission, 2010). Assuming gambling harm is associated with an unsatisfactory quality of life, several studies have shown a strong relationship mediated by severe depression and indebtedness between gambling harm and suicidal thoughts, attempted suicide and completed suicide (Serpelloni, 2013).

In a sample of over 7,000 individuals, Newman and Thompson (2003) find that gambling harm is associated with higher probability of suicide attempts (odds ratio $=3.95$, statistically significant). This is also confirmed by Park and colleagues (2010), who analyzed gambling harm prevalence, clinical correlations, comorbidities and suicidality in 5,333 adults. Wong et al. (2010) note that among 1,201 victims of suicide, $19.4 \%$ gambled 
before dying: of these, $47.2 \%$ - mostly males, 30-49 years, married, unemployed - had debts in connection with gambling. A very recent study by Wardle and McManus (2021) confirms the association between high-risk gambling and suicide for young people (16-24 years of age).

In general, literature suggests that suicidal ideation and suicide attempts are common in high-risk gamblers, while it is less clear whether the association is spurned by other factors, such as substance abuse or psychiatric disorders (Hodgins et al. 2006). Black et al. (2015), analyzing the prevalence of suicide in 95 highrisk gamblers and 1,075 families (parents and children), find significant differences in suicidal ideation between high-risk gamblers and a control group (OR $=3.91$ ). Ronzitti et al. (2017), focusing on treatment seekers for gambling harm, report that $46 \%$ of the sample have suicidal ideations and those who admit such thoughts also present greater severity in gambling harm, levels of depression and anxiety. An Australian study (APC 1999), finds that the number of suicides among high-risk gamblers are 5-10 times higher than in general population. A recent study from Sweden finds a 15 -fold increase in suicide mortality for individuals 20-74 years old with a gambling disorder compared to the general population (Karlsson \& Hakansson, 2018).

The most recent data on suicides (3,048 individuals) and suicide attempts $(3,101)$ in the Italian adult population refer to the survey conducted by ISTAT. This is based on evidence collected by judicial authorities and public security forces, and dates back to 2012. This data was analyzed using the framework of economic evaluation of human life.

Several methods to estimate the value of human life are used in the theoretical and empirical literature (Viscusi \& Aldy, 2003). In economic theory, more properly in the cost-benefit analysis of public policies, it is common practice to estimate the value indirectly assigned to people's life and health. In particular, both the State expenditure to keep people in good health and the contribution healthy individuals would accordingly give to the added value of a country (e.g., values estimated by insurance companies or derived from transport studies) are relevant. According to the outlined approach (Falvo \& Marabucci, 2008; Robinson \& Hammit, 2017), estimates should include the cost incurred by the government for health and social security (i.e., expenditure charged to the National Health System, social protection expenditures), the contribution to the Total Value Added lost as a result of a death, the average productivity, and life expectancy. The average age of high-risk gamblers in the CIRMPA dataset is equal to 46.45 , while life expectancy was 83.09 in 2014. Thus, the average high-risk gambler faced on average 36.64 years of life left. Considering that the gross annual average income in Italy in 2014 was $29,472^{5}$, we compute the value of a lost human life as $29,472 \times 36,64=1,079,854.08 E U R$

In computing the number of suicides applicable to high-risk gamblers, we adopted a conservative approach and used the results found by the Australian study (APC, 1999), according to which the incidence of suicides in the population of high-risk gamblers is 5 times higher than that in the general population of nongamblers, rather than using higher values of 10 and 15 , as done in other studies aimed at computing the social costs of gambling (Winkler et al., 2017; Hofmarcher et al., 2020). Incidence of suicide in the adult population is equal to 0,00006 (ptot=3048/50624663). We applied the formula presented in footnote 3 using a relative risk of 5 and computed the suicide incidence for high-risk gamblers in Italy to be equal to 0.00027 . This incidence was then multiplied by the number of high-risk and at risk gamblers $(1,230,179)$ : thus, we computed a total of 338 suicides. Since the relationship between gambling and suicide is hard to interpret as causal, we apply the discount rate of $20 \%$ as discussed above, and attribute to 270 suicides to gambling harm. Using this number, and multiplying it by the value of a life, it was possible to estimate the costs of suicidality and suicide as follows:

\section{$270 \times 1,079,854=$ EUR 291,6 million}

\section{Family Costs}

Afifi et al. (2010) suggest that there is a greater propensity for gambling harm among separated and divorced males. According to the hypothesis that excessive gambling and marital status are associated, most of the individuals identified by Lyk-Jensen (2010) are singles, separated and divorced. Even more recent studies recognize associations between gambling harm and the profile of the divorced male gambler (lliceto et al., 2016). Similarly, exploring relevant events over the previous 12 months, CIRMPA shows that social gamblers' divorce/separation rate is approximately a quarter (4.05) of high-risk gamblers' rate (2.2 compared to 8.9). Finally, Wenzel et al. (2008) estimate a 2.6 fold increase in high-risk gamblers' divorce rate compared to general population in Norway. A similar relative risk was found by Black et al (2012). In 2014, in Italy the budget of the Ministry of Justice was about EUR 7,553 million and proceedings were 6,567,003 - annual cost of each proceeding equal to EUR 1,150. In particular, there were 61,229 consensual separations, 33,767 consensual divorces, 40,174 judicial separations and 25,689 judicial divorces, for a total of 160,859 (Ministry of Justice 2017). So, it was possible to calculate the number of divorces and separations related to high-risk gambling as equal to 9,782 , which was then discounted

\footnotetext{
${ }^{5}$ Retrieved from ISTAT (2016).

https://www.istat.it/it/files//2016/12/EN_Income-and-living-

conditions.pdf
} 
by $20 \% ; 7,826$ is thus the number we used to compute the cost:

7826 XEUR 1,150 = EUR 9 million

\section{Crime and Legal Costs}

In many individuals risk-taking propensity - harmful behaviors, drug use, crimes, dangerous driving - and gambling harm coexist (Johansson et al., 2009; Mishra et al., 2016). Significant are the criminogenic effects of gambling demonstrated by the higher incidence of arrests and imprisonments among high-risk gamblers (Lesieur, 1998). In particular, severe gambling harm is associated with economic crime, such as theft, counterfeiting and fraud. Gamblers' need for money is associated with crime and an uncertain number of offenders, in relation to the type of crime, victims reaction and the attitudes of public authorities. In case of crimes committed at work and against relatives and friends, judicial proceedings are rare due to relationship intimacy and distrust about the possibility of recovering stolen assets (Bianchetti \& Croce, 2007). Although some habitual offenders become high-risk gamblers during their lifetime, high-risk gamblers often start to commit offenses in order to fund gambling (Lind et al., 2015). Moreover, an emerging body of research has documented an association between gambling harm and domestic violence (Markham et al., 2016).

Several studies show that is quite common for highrisk gamblers to have committed gambling-related crimes. Relevant are cases of gambling-related embezzlement in the workplace, as shown by a classic study (Lesieur, 1984) according to which about one high-risk gambler out of three would have committed that crime. This is supported more recently by Binde (2017), in a study dealing with misappropriation in the workplace. This crime occurs in all economic sectors where employees and workers have access to large amount of money for prolonged periods. Undue appropriation in the workplace usually occurs when offenders, considered trustworthy, take money in the hope of recovering losses and returning the stolen goods in order to hide their gambling problems.

Such a crime undoubtedly represents a relevant issue, as it not only causes economic damage to the employer, but also implies additional costs to intensify control over employees. In Australia, 15\% of offenders convicted of major fraud cited gambling as a reason for their crime (Sakurai \& Smith, 2003), and 15-20\% of the cases of theft committed by employees at work are linked to gambling behaviors (Crofts, 2003). These results are corroborated by research conducted in Norway (Buvik, 2009) where $10 \%$ of high-risk gamblers have stolen money from their colleagues, 20\% 'borrowed' employer's money and $11 \%$ stole money at work. In a US study focused on embezzlement (2008-

\footnotetext{
${ }^{6}$ We followed, once again, the procedure explained in the section Calculation of costs.
}

2012), almost a third of cases were gambling-related (Marquet International, 2013).

\section{Judicial System Costs}

Considering the previous 12 months, CIRMPA data shows that the proportion of high-risk gamblers having a legal problem is approximately double (2.18) that of social gamblers. As noted, in 2014 the budget of the Ministry of Justice was about EUR 7,553 million and the annual cost of each proceeding equal to EUR 1,150 (Ministry of Justice, 2017). The total number of proceedings - minus proceedings relating to minors (not included in the population of interest of the study) - was 6,275,722. We proceeded as follow: first we computed the risk of having a legal problem for the whole population as $12.9 \%(6,275,722 / 50,624,663)$. Using this figure, the share of high-risk gamblers and the relative risk, we computed the number of proceedings due to high-risk gambling ${ }^{6}$, which was then reduced by $20 \%$. We found that around 258,546 proceedings were related to gambling harm.

Therefore, it was possible to calculate as follows:

\section{8,546 XEUR 1,150= EUR 297.3 million}

\section{Penitentiary System Costs}

The prison population is very vulnerable to gambling harm. The association is confirmed in the different countries where specific research has been conducted (Wardle et al., 2011). May-Chahal et al. (2017) investigate the association between criminal careers and gambling, analyzing a sample of 1,057 detainees (male and female) of English and Scottish prisons. In line with previous studies, the overall prevalence of gambling harm in the prison sample was significantly higher than in the general population ( $12 \%$ vs. $0.7 \%)$. Compared to the national sample, is noteworthy that a smaller percentage of prisoners detained within 12 months gambled without problems ( $23 \%$ vs $64.9 \%$ of the general population). Furthermore, it is noteworthy that the crimes that have led high-risk gamblers to incarceration are possession/supply/importation of drugs (26.7\%), theft and fraud/forgery (both at 20\%), but not violent crimes. Severe loss-chasers and serious high-risk gamblers (6.8\%) are likely to need more intensive therapeutic interventions. This reflects the wider literature on antisocial personality, gambling and delinquency (Turner et al., 2016) according to which rates in the prison population vary from $5.2 \%$, ranging from 3 to 19 times the level in the general population (Hickey et al., 2014). Turner et al. (2009) report a 9.4\% overall prevalence of gambling harm in a prison sample $(\mathrm{N}=254)$, compared to $1.14 \%$ of the Canadian general population, which is equal to a relative risk of 8.25 . Of the high-risk gamblers prison sample, $65 \%$ reported 
having committed illegal activities as a result of gambling, in particular to pay gambling-related debts.

Choosing - also in this case - a conservative approach, considering that daily per-person cost of prison in Italy reached EUR 190,21 in 2013 (Ministry of Justice, 2014) and that the number of adult prisoners in the country was 53,623 in December 2014 (ISTAT, 2015), it was possible to calculate how many high-risk gamblers were in prison - 9,139 - by using the imprisonment rate in the general population, the share of high-risk gamblers and the relative risk ${ }^{7}$. We generated an estimate discounted by $35 \%$, since about $65 \%$ of high-risk gamblers in prison were found to be there due to illegal actives committed as a result of gambling $^{8}$. Thus, we end up with 5,940 individuals in prison due to gambling harm:

\section{5,940* $($ EUR 190,21 X 365) $=$ EUR 412.5 million}

Therefore, crime and legal costs were estimated in:

EUR 297.3 million + EUR 412.5 million $=$ EUR 709,8 million

\section{Discussion}

In 2014, the overall social costs of gambling in Italy summarized in Table 4 - were estimated to be EUR 2,324 million. Our estimates of the social costs of gambling harm in Italy demonstrate a substantial economic burden to society ${ }^{910}$.

Table 4. Social Costs of Gambling in Italy (million)

\begin{tabular}{llll}
\hline Health Costs & Treatment & 10.2 & 60.2 \\
& Other costs* & 50 & \\
Unemployment \& productivity Costs & Unemployment & 383.3 & $1,253.4$ \\
Suicide costs & Productivity losses & 870.1 & 291.6 \\
Family costs & Suicide costs & 291.6 & 9 \\
Crime and legal costs & Separations \& divorces & 9 & 709.8 \\
\hline TOTAL cost & Judicial system & 297.3 & EUR 2,324 \\
\hline
\end{tabular}

While the highest costs are associated with unemployment and lost productivity, costs related to treatment are relatively low, in line with a quite recent Czech study (Winkler et al., 2017). To the best of our knowledge, ours is the first study to systematically assess social costs of gambling in Italy, built on solid epidemiological evidence and potentially useful for the further development of gambling-related regulation. Based on budgetary considerations, Italian government revenues are higher than the expenses generated by the health system and welfare to compensate for the negative externalities of trade and use of gaming products. In fact, in 2014 public gaming revenues totaled EUR 84,5 billion, of which EUR 7,9 billion went to

\footnotetext{
${ }^{7}$ Using the procedure explained in the section Calculation of costs.

${ }^{8}$ We apply this discount rate which is higher than $20 \%$ applied elsewhere to be even more cautious.

9 As already mentioned, the Australian Productivity Commission estimates that between 5 and 10 others are affected by harmful gambling $(1999 ; 2000)$ and more recent work has suggested an average of six (Goodwin et al. 2017): hence, considering a social cost per gambler of $2,211 €$, indirect costs greater than $369 €$ (a sixth of $2,211 €)$ are sufficient to outweigh the direct costs associated with high-risk gamblers themselves.
}

the government. Gamblers' expenditure was EUR 16,9 billion (Customs and Monopolies Agency, 2015). ${ }^{11}$

However, three recommendations are needed. Firstly, the well-being of a population is not measured only by economic indicators. Across the globe there is growing skepticism about the usefulness of GDP as a sole measure of national well-being. Consequently, several alternative quality-of-life measures were developed which aim to complement GDP, adding important insights to it in order to search for a widely accepted comparable measure of well-being (Delhey \& Kroll, 2013). Secondly, the spread of gambling also produces cultural, ethical and social effects that are very difficult to measure and quantify at the moment. This

\footnotetext{
${ }^{10}$ On a per capita basis, social costs of gambling in Italy were estimated to be EUR38, compared, for instance, to EUR 4 in Germany (reference year: 2008), EUR 52-59 in Czech Republic (2012), EUR 715 in Victoria/Australia (2014-15) (see Table 1).

${ }^{11}$ In 2018 public gaming revenues totaled $€ 106,8$ billion, of which $€ 10,4$ billion went to the State. Gamblers' expenditure was $€ 18,9$ billion. According to the 2019 data, which is not definitive, overall gambling spending is increasing by $2.7 \%$ compared to 2018 (Customs and Monopolies Agency, 2019; 2020).
} 
spread is likely to produce changes in gambling culture that influence individual and collective identity in the medium and long term (Fea, 2017). Again, as Adams (2016) has identified, there are significant risks associated across society (including amongst regulators, policy makers and community organizations) when dependency on gambling revenue is established, and these risks should be considered in further reflections on social costs. Thirdly, the results of this study must be taken with caution as it presents limitations which are mostly methodological in nature, reflecting the current state of art in the field. Fourthly, the burden of disability is not incorporated into these costs (Browne et al., 2018) and would add to them significantly.

A shared methodology on social costs is desirable in order to identify, measure and quantify the effects associated with gambling, and to provide consistent scientific evidence to policy-making, offering comparisons between different geographic areas and testing the effectiveness of preventive and treatment measures. More generally, the critical issues affecting social costs estimates are linked to limited comparability of research, not only due to differences in health systems and jurisdictions. Also noteworthy is the absence of a standard terminology to describe the effects of harmful behaviors/addictions, measure the overall loss of social well-being and analyze the factors creating diseconomies and potential loss of income for communities.

Moreover, relevant confounding factors should be considered as well. For example, the relative weight of substance use and abuse (drugs, alcohol, smoking, etc.) and its impact on social costs of gambling harm could not be estimated in the present study. That is also true with regard to psychiatric co-morbidities. Furthermore, it is necessary to recognize the difficulty in clarifying the temporal relationship between gambling harm and critical situations such as unemployment, suicidality, deviant behavior, etc. In addition, future estimates will have to consider that social security benefits, tax systems and the overall economic situation could be unstable over time.

Other kind of limitations stem from data availability and reliability. First, the estimation of gambling harm prevalence is far from conclusive in Italy: just consider how the total amount of costs vary when we work under the assumption of a different number of high-risk gamblers, as illustrated in Table A1. Second, quantification of health and social care costs was preceded by some assumptions and concerned just a part of addictions services in Italy because a larger analysis would have been resource-demanding, exceeding the aim of this study. Some epidemiological data - such as that concerning unemployment and productivity losses, suicides, divorces and separations, judicial and penitentiary systems - come from surveys which were not specifically conducted to estimate the social costs of gambling harm. Much of the data used refers only to gamblers (excluding minors), while other studies are related to the general population. This creates distortions of estimates, considering a limited number of calculated costs.

The costs have therefore been underestimated, overall. In some cases they are limited to those of a public nature, and do not take into consideration, for example, externalities that also affect individuals, such as the families involved for each high-risk gambler. In other words, only the effects on public finance have been considered and in a non-exhaustive way - i.e., resources that could have been used in productive activities and invested in consumption, effects produced on public finances by usury and other illegalities, indirect health costs impacting on other dimensions of health and health spending beyond treatment of high-risk gamblers.

Table A1. Different scenarios

\begin{tabular}{llll}
\hline & $\begin{array}{l}\text { Our estimates } \\
\text { (CIRMPA) }\end{array}$ & $\begin{array}{l}\text { Department of Anti- } \\
\text { Drug Policies 2015 }\end{array}$ & $\begin{array}{l}\text { National Institute of } \\
\text { Health } 2018\end{array}$ \\
$\begin{array}{l}\text { High-risk and at risk } \\
\text { gamblers }\end{array}$ & $1,230,179$ & 767,000 & 296,000 \\
$\begin{array}{l}\text { Health Costs } \\
\text { Unemployment and } \\
\text { productivity Costs }\end{array}$ & 60.2 & 60.2 & 60.2 \\
Suicide costs & $1,253.4$ & 781,5 & 2339,4 \\
Family costs & 291.6 & 187.9 & 505.4 \\
Crime and legal costs & 9.0 & 5.7 & 16.3 \\
\hline
\end{tabular}




\section{References}

Adams, J.P. (2016). Moral Jeopardy: risks of accepting money from the alcohol, tobacco and gambling industries. Cambridge University Press.

Afifi, T.O., Cox, B.J., Martens, P.J., Sareen, J., \& Enns, M.W. (2010). The relation between types and frequency of gambling activities and problem gambling among women in Canada. The Canadian Journal of Psychiatry, 55(1), 21-28. https://doi.org/10.1177/070674371005500104

Anielski, M., \& Braaten, A. (2008). The socio-economic impact of gambling (SEIG) framework. An assessment framework for Canada. In search of the gold standard. Inter-Provincial Consortium for the Development of Methodology to Assess the Social and Economic Impact of Gambling, February 2008. https://prism.ucalgary.ca/handle/1880/45235

Australian Productivity Commission [APC] (1999). Australia's Gambling Industries. Report no. 10. https://www.pc.gov.au/inquiries/completed/gambling/report

Barbaranelli, C., Vecchione, M., Fida, R., \& Podio-Guidugli, S. (2013). Estimating the prevalence of adult problem gambling in Italy with SOGS and PGSI. Journal of Gambling Issues, 28, 1-24. https://doi.org/10.4309/jgi.2013.28.3

Barbaranelli, C. (2015). La realtà italiana. Il gioco problematico in Italia: prevalenza, fattori di protezione e di rischio, Centro Interuniversitario per la Ricerca sulla Genesi e sullo Sviluppo delle Motivazioni Prosociali e Antisociali (CIRMPA) Università La Sapienza di Roma. Gioco d'Azzardo, società, istituzioni, servizi, organizzato dalla Federazione Italiana degli Operatori dei Dipartimenti e dei Servizi delle Dipendenze (FeDerSerD), Milano 10-11 novembre 2015.

Barrio, P., Reynolds, J., García-Altés, A., Gual, A., \& Anderson, P. (2017). Social costs of illegal drugs, alcohol and tobacco in the European Union: A systematic review. Drug and Alcohol Review, 36(5), 578-588. https://doi.org/10.1111/dar.12504

Becker, T. (2011). Soziale kosten des Glucksspiels in Deutschland, Lang.

Bertolazzi, A. (2016). Il gioco d'azzardo sfida i Ser.T.: uno studio di caso. Salute e Società, 15(2), 103-118.

Bianchetti, R., \& Croce, M. (2007). Il crescente mercato del gioco d'azzardo in Italia: violenza nascosta o indifferenza collettiva? Questioni sui costi sociali e sui... 'legittimi' guadagni. Sociologia del diritto, 2(2), 113-158.

Binde, P. (2017). Gambling-related employee embezzlement: A study of Swedish newspaper reports. Journal of Gambling Issues, 34, 12-31. https://doi.org/10.4309/jgi.2016.34.2

Black, D.W., Coryell, W., Crowe, R., McCormick, B., Shaw, M., \& Allen, J. (2015). Suicide ideations, suicide attempts, and completed suicide in persons with pathological gambling and their firstdegree relatives. Suicide and life-threatening behavior, 45(6), 700-709. https://doi.org/10.1111/sltb.12162

Black, D.W., Shaw M.C., McCormick B.A., Allen J. (2012). Marital status, childhood maltreatment, and family dysfunction: a controlled study of pathological gambling. J Clin Psychiatry, 73(10), 1293-7. https://doi.org/10.4088/JCP.12m07800

Browne, M., Greer, N., Armstrong, T., Doran, C., Kinchin, I., Langham, E. \& Rockloff, M. (2017). The social cost of gambling to Victoria. Victorian Responsible Gambling Foundation, Melbourne. http://www.responsiblegambling.vic.gov.au/information-andresources/research/recent-research/the-social-cost-ofgambling-in-victoria

Buvik, K. (2009). To gamble with the jobs — Problem gambling in working life. Oslo, Norway: AKAN.

Collins, D., \& Lapsley, H. (2003). The Social Costs and Benefits of Gambling: An Introduction to the Economic Issues. Journal of Gambling Studies, 19(2),123-148. https://doi.org/10.1023/A:1023677214999
Crofts, P. (2003). Problem gambling and property offences: An analysis of court files. International Gambling Studies, 3, $183-$ 197. https://doi.org/10.1080/1356347032000142289

Custer, R. (1982). An overview of compulsive gambling. In Caron P.A., Yolles, S.F., Kieffen, S.N. (Eds.), Addictive disorders update: Alcoholism, drug abuse, gambling. Human Science Press.

Customs and Monopolies Agency (ADM) (2015). Organizzazione, attività e statistica. Anno 2014. http://www.agenziadoganemonopoli.gov.it/

Customs and Monopolies Agency (ADM) (2019). Libro Blu 2018. Retrieved on

https://www.agenziadoganemonopoli.gov.it/portale/documen ts/20182/4025137/pas-a-20180507bilancioesercizio2017.pdf/2a596b7b-bf4d-4d03-b7c0c1 aa5816bb40, 21 August 2019.

Customs and Monopolies Agency (ADM) (2020). Retrieved on https://www.adm.gov.it/portale/monopoli/giochi, 7 April 2020.

D'angela, D., Polistena, B., \& Spandonaro, F. (2019), La misura della Performance dei SSR del C.R.E.A. Tor Vergata-Sanità, Roma. Retrieved from http://www.quotidianosanita.it/allegati/allegato8783228.pdf, 16 July 2019.

Delfabbro, P. (2013). Problem and pathological gambling: a conceptual review. The Journal of Gambling Business and Economics, 7(3), 35-53. https://doi.org/10.5750/jgbe.v7i3.817

Delhey, J., \& Kroll, C. (2013). A "happiness test" for the new measures of national well-being: How much better than GDP are they? In Human happiness and the pursuit of maximization (pp. 191-210). Springer.

Demoskopika. (2017). Indice Performance Sanitaria 2016 (Allegato metodologico). Retrieved from http://www.quotidianosanita.it/allegati/allegato2641676.pdf, 4 January 2017.

Department of Anti-Drug Policies (2015). Relazione annuale al parlamento 2016 sullo stato delle tossicodipendenze in Italia.

Department of Anti-Drug Policies (2016). Relazione annuale al parlamento 2016 sullo stato delle tossicodipendenze in Italia.

Falvo, A., \& Marabucci, A. (2008). L'analisi costi benefici applicata alle infrastrutture di trasporto (No. 0087). Department of EconomicsUniversity Roma Tre.

Fea, M. (2017). Le abitudini da cui piace dipendere. Algoritmi, azzardo, mercato, web. FrancoAngeli.

Godfrey, C., Hutton, S., Bradshaw, J., Coles B., Craig, G., \& Johnson, J. (2002). Estimating the cost of being "Not in education, employment or training" at age 16-18. Queen's Printer.

Goodwin, B.C., Browne, M., Rockloff, M. \& Rose J. (2017). A typical problem gambler affects six others. International Gambling Studies, 17 (2), 276-289. https://doi.org/10.1080/14459795.2017.1331252

Grant, J.E., \& Potenza, M.N. (Ed.) (2004). Pathological gambling: A clinical guide to treatment. American Psychiatric Publishing.

Hickey, K., Kerber, C., Kim, S.A., MyoungJin, K., \& Schlenke, E. (2014). Perceived health and gambling behavior of inmates: A review of the literature. Nursing Forum, 49(4), 247-258. https://doi.org/10.1111/nuf.12055

Iliceto, P., D'Antuono, L., Bowden-Jones, H., Giovani, E., Giacolini, T., Candilera, G., Sabatello, U., \& Panksepp, J. (2016). Brain emotion systems, personality, hopelessness, self/other perception, and gambling cognition: A structural equation model. Journal of Gambling Studies, 32(1), 157-169. https://doi.org/10.1007/s10899-015-9543-0

Hodgins, D.C., Mansley, C., \& Thygesen K. (2006). Risk factors for suicide ideation and attempts among pathological gamblers. The American Journal on Addictions, 15(4), 303-310. https://doi.org/10.1080/10550490600754366 
Hofmarcher, T., Romild, U., Spångberg, J. et al. (2020). The societal costs of problem gambling in Sweden. BMC Public Health, 20(1), 1-14. https://doi.org/10.1186/s12889-020-10008.

Italian National Institute of Statistics (ISTAT) (2012). Suicidi e tentativi di suicidio. https://www.istat.it/it/archivio/55646

Italian National Institute of Statistics (ISTAT) (2014). Retrieved from http://demo.istat.it/pop2014/index.html, 3 October 2017.

Italian National Institute of Statistics (ISTAT) (2015). Retrieved from http://dati.istat.it/index.aspx?queryid=6189, 18 September 2017.

Italian National Institute of Statistics (ISTAT) (2016). Income and living conditions Year 2015.

https://www.istat.it/it/files//2016/12/EN_Income-and-livingconditions.pdf

Italian Parliament (2015). Law 208/2015, Disposizioni per la formazione del bilancio annuale e pluriennale dello Stato (legge di stabilità 2016). (15G00222) (GU Serie Generale n.302 del 30-12-2015 Suppl. Ordinario n. 70)

Jeanrenaud, C., Gay, M., Kohler, D., Besson, J., \& Simon O. (2012). Le coût social du jeu excessif en Suisse. Institut de recherches économique de Neuchâtel, Centre du jeu excessif.

Johansson, A., Grant, J. E., Kim, S. W., Odlaug, B. L., \& Götestam K. G. (2009). Risk factors for problematic gambling: A critical literature review. Journal of Gambling Studies, 25(1), 67-92. https://doi.org/10.1007/s10899-008-9088-6.

Karlsson, A. \& Hakansson, A. (2018). Gambling disorder, increased mortality, suicidality, and associated comorbidity: A longitudinal nationwide register study. Journal of Behavioral Addictions 7(4), 1091-1099. https://doi.org/10.1556/2006.7.2018.112

Kohler, D. (2014). A monetary valuation of the quality of life loss associated with pathological gambling: An application using a health utility index. Journal of Gambling Issues, 29, 1-23. https://doi.org/10.4309/jgi.2014.29.9

Korn, D., R. Gibbins, \& J. Azmier, (2003). Framing Public Policy Towards a Public Health Paradigm for Gambling. Journal of Gambling Studies,19(2), 235-256. https://doi.org/10.1023/A:1023685416816

Lesieur, H.R. (1984). The chase: Career of the compulsive gambler (2nd ed.). Schenkman.

Lesieur, H.R. (1998). Costs and treatment of pathological gambling. The Annals of the American Academy of Political and Social Science, 556(1), 153-171. https://doi.org/10.1177/0002716298556001012

Lind, K., Kääriäinen, J., \& Kuoppamäki, S.M. (2015). From problem gambling to crime? Findings from the Finnish National Police Information System. Journal of Gambling Issues, 30, 98-123. https://doi.org/10.4309/jgi.2015.30.10

Livingstone, C., \& Rintoul, A. (2021). Gambling-related suicidality: Stigma, shame, and neglect. The Lancet Public Health, 6(1), e4e5. https://doi.org/10.1016/S2468-2667(20)30257-7

Lovaste, R., Grech, M., Pellegrini, G., \& Molin V. (2016). Procedura per la valutazione costo efficacia dei trattamenti per il gambling. il Lucchini A. (Ed.), Il gioco d'azzardo patologico. Esperienze cliniche, strategie operative e valutazione degli interventi territoriali, FrancoAngeli.

Lucchini, F., Comi, S. (2018). I costi sociali del gioco d'azzardo problematico in Italia. https://www.federserd.it/files/novita/Rapporto\%20di\%20ricerc a\%20costi\%20sociali_DEF.pdf

Lyk-Jensen, S.V. (2010). New evidence from the grey area: Danish results for at-risk gambling. Journal of Gambling Studies, 6(3), 455-67. https://doi.org/10.1007/s10899-009-9173-5

Markham, F., Doran, B., \& Young, M. (2016). The relationship between electronic gaming machine accessibility and police-recorded domestic violence: A spatio-temporal analysis of 654 postcodes in Victoria, Australia, 2005-2014. Social Science \& Medicine, 162, 106-114. https://doi.org/10.1016/j.socscimed.2016.06.008
Maschio, S. (2016). Durata e caratteristiche degli episodi di disoccupazione: I'applicazione di un modello di stima su dati amministrativi. Veneto Lavoro.

https://www.venetolavoro.it/documents/10180/3823842/Durat a\%20disoccupazione.pdf

Marquet International (2013). The 2012 Marquet report on embezzlement. Marquet International.

http://www.marquetinternational.com/register.php?target=tra ckpdfs/the_2012 marquet report on embezzlement.pdf

May-Chahal, C., Humphreys, L., Clifton, A., Francis, B., \& Reith, G. (2017). Gambling harm and crime careers. Journal of Gambling Studies, 33(1), 65-84. https://doi.org/10.1007/s10899-016-9612-z

Ministry of Health (2016). Decreto del Ministero della Salute. Ripartizione Fondo per il gioco d'azzardo patologico, 6 ottobre 2016. Retrieved from http://www.trovanorme.salute.gov.it/norme/renderNormsanPd f?anno $=2016 \&$ codLeg $=56900$ \&parte $=1 \% 20 \&$ serie $=$ null, 14 December 2017.

Ministry of Justice (2014). Costo medio giornaliero per detenuto - Anni 2001-2013.

https://www.giustizia.it/giustizia/it/mg 114 1.page?contentld =SST957890\&previsiousPage=mg 14 7, 31 August 2017.

Ministry of Justice (2017). Relazione sull'amministrazione della giustizia nell'anno 2017. Retrieved from https://www.giustizia.it/giustizia/it/mg 215 7.page, 11 September 2017.

Mishra, S., Lalumière, M.L., \& Williams, R. J. (2016). Gambling, risktaking, and antisocial behavior: A replication study supporting the generality of deviance. Journal of Gambling Studies. https://doi.org/10.1007/s10899-016-9608-8

National Institute of Health (ISS) (2018). Retrieved from https://ufficiostampa.iss.it/?p=1335, 18 October 2018.

National Institute of Social Security (INPS) (2015). Retrieved from https://www.inps.it/nuovoportaleinps/default.aspx?itemDir=50 707, 3 April 2017.

National Institute for Social Security (INPS) (2015). Rapporto annuale 2014.

https://www.inps.it/docallegatiNP/Mig/Allegati/2101Inps_Rapp orto annuale 2014.pdf

Neal, P., Delfabbro, P., \& O'Neil, M. (2005). Problem gambling and harm: Towards a national definition, prepared for the national Ministerial Council on gambling (Gambling Research Australia). South Australian Centre for Economic Studies with the Department of Psychology, University of Adelaide, Victorian Government.

https://www.gamblingresearch.org.au/sites/default/files/201910/Problem\%20Gambling\%20and\%20Harm\%20\%20Towards\%20a\%20National\%20Definition\%202005.pdf

Newman, S.C., \& Thompson, A.H. (2003). A population-based study of the association between pathological gambling and attempted suicide. Suicide and Life-Threatening Behavior, 33(1), 80-87. https://doi.org/10.1521/suli.33.1.80.22785

Park, S., Cho, M. J., Jeon, H. J., Lee, H. W., Bae, J. N., Park, J. I., ... \& Hong, J.P. (2010). Prevalence, clinical correlations, comorbidities, and suicidal tendencies in pathological Korean gamblers: Results from the Korean Epidemiologic Catchment Area Study. Social psychiatry and psychiatric epidemiology, 45(6), 621-629. https://doi.org/10.1007/s00127-009-0102-9

Productivity Commission (1999). Australia's gambling industries. Report no. 10. Canberra, Australia. Available at: http://www.pc.gov.au/inquiries/completed/gambling/report.

Productivity Commission (2010). Gambling. Report no. 50. http://www.pc.gov.au/projects/inquiry/gambling-2009/report.

Robinson, L.A., \& Hammitt, J.K. (2017). Benefit-cost analysis in global health. In O. F. Norheim, E. J. Emanuel, \& J. Millum (Eds.), Global health priority-setting: Beyond cost-effectiveness (pp. 103-122). Oxford University Press. 
Ronzitti, S., Soldini, E., Smith, N., Potenza, M.N., Clerici, M., \& BowdenJones, H. (2017). Current suicidal ideation in treatment-seeking individuals in the United Kingdom with gambling problems. Addictive behaviors, 74, 33-40. https://doi.org/10.1016/j.addbeh.2017.05.032

Sakurai, Y., \& Smith, R.G. (2003). Gambling as a motivation for the commission of financial crime. Trends \& Issues in Crime and Criminal Justice, 256. http://www.aic.gov.au/media_library/publications/tandi_pdf/ta ndi256.pdf

Serpelloni, G. (2013). Gambling. Gioco d'azzardo problematico e patologico: inquadramento generale, meccanismi fisio-patologici, vulnerabilità, evidenze scientifiche per la prevenzione, cura e riabilitazione. Manuale per i Dipartimenti delle Dipendenze. Dipartimento Politiche Antidroga.

Single, E., Collins, D., Easton, B., Harwood, H., Lapsley, H., Kopp, P., \& Wilson, E. (2003). International guidelines for estimating the costs of substance abuse. World Health Organization.

Turner, N. E., Preston, D. L., Saunders, C., McAvoy, S., \& Jain, U. (2009) The relationship of problem gambling to criminal behavior in a sample of Canadian male federal offenders. Journal of Gambling Studies, 25(2), 153-169. https://doi.org/10.1007/s10899-0099124-1

Turner, N.E., Stinchfield, R., McCready, J., McAvoy, S., \& Ferentzy, P. (2016). Endorsement of criminal behavior amongst offenders: Implications for DSM-5 gambling disorder. Journal of Gambling Studies, 32, 35-45. https://doi.org/10.1007/s10899-015-9540-3

Viscusi, W.K., \& Aldy, J.E. (2003). The value of a statistical Life: A critical review of market estimates throughout the world. Journal of Risk and Uncertainty, 27(1), 5-76. https://doi.org/10.1023/A:1025598106257

Walker, D.M. (2007). Problems in quantifying the social costs and benefits of gambling. American Journal of Economics and Sociology, 66(3), 611-614. https://doi.org/10.1111/j.15367150.2007.00529.x

Walker, D.M., \& Barnett, A. H. (1999). The social costs of gambling: An economic perspective. Journal of Gambling Studies, 15(3), 181 185. https://doi.org/10.1023/A:1023089111024

Wardle, H. et al. (2011). British gambling prevalence survey 2010. London: National Centre for Social Research. http://www.gamblingcommission.gov.uk/PDF/British\%20Gamb ling\%20Prevalence\%20Survey\%202010.pdf.

Wardle H. \& McManus, S. (2021). Suicidality and gambling among young adults in Great Britain: results from a cross-sectional online survey. Lancet Public Health, 6(1). https://doi.org/10.1016/S2468-2667(20)30232-2.

Wenzel, H.G., Øren, A. \& Bakken, I.J. (2008). Gambling problems in the family - A stratified probability sample study of prevalence and reported consequences. BMC Public Health, 8(412). https://doi.org/10.1186/1471-2458-8-412.

Winkler, P., Bejdová, M., Csémy, L., \& Weissová, A. (2017). Social Costs of Gambling in the Czech Republic 2012. Journal of gambling studies, 33(4), 1293-1310. https://doi.org/10.1007/s10899-0169660-4

Wong, P.W., Cheung, D.Y., Conner, K.R., Conwell, Y., \& Yip, P.S. (2010). Gambling and completed suicide in Hong Kong: A review of coroner court files. Primary care companion to the Journal of clinical psychiatry, 12(6). https://doi.org/10.4088/PCC.09m00932blu

\section{Funding and Conflict of Interest Statement}

This study was funded by FeDerSerD (Italian Federation of Workers of the Addiction Departments and Services). Over the last three years, Fabio Lucchini has received funding from the following projects and grants: 2020 "Research on online interventions for gambling disorder" funded by FeDerSerD, Senior researcher.
2019 "Research and literature review on gambling disorder" funded by FeDerSerD, Senior researcher. Over the last three years, Simona Comi has received funding from the following projects and grants: 2021 "Evaluation of Youth Guarantee In Lombardy" project funded by the Lombardy Region, Joint Coordinator. 2020 "Evaluation of Tertiary Vocational Education In Lombardy" project funded by the Lombardy Region, Joint Coordinator.

2019 "Evaluation of the impact of Apprenticeship Type I In Lombardy" project funded by the Lombardy Region, joint Coordinator.

\section{Acknowledgements}

We thank Prof. Claudio Barbaranelli, University of Rome "La Sapienza" for methodological discussions during the course of this study and to Dr. Maurizio Fea, FeDerSerD (Italian Federation of Workers of the Addiction Departments and Services) for critically reviewing previous version of this manuscript.

\section{Author Details}

Fabio Lucchini is an Adjunct Professor of Sociology at the Faculties of Law and Psychology of eCampus University. He holds a Ph.D in Applied Sociology and Social Research Methodology from University of MilanoBicocca, his research interests lie primarily in the fields of sociology of health and behavioral addictions, with a specific focus on socio-economic inequalities and their relationship with individual and collective well-being and lifestyles.

Simona Comi is Associate Professor of Economics at the Department of Business and Law at the University of Milano Bicocca. She holds a Ph.D. in Economics from University of Milano. She has 20 years of experience of empirical research in several national and international studies on educational and labour markets related policies, including youth labour markets, college choice, school-to-work transitions, vocational education and apprenticeship, education and training systems, ICT and teacher quality.

\section{ORCID}

Fabio Lucchini (iD)

https://orcid.org/0000-0002-6092-1907

Simona Lorena Comi iD

https://orcid.org/0000-0003-4921-4483 